\title{
- Pigmented Basal Cell Carcinoma - A Rare Case Report
}

IJCRR
Section: Healthcare
ISI Impact Factor
$(2019-20): 1.628$
IC Value (2019): 90.81
SJIF (2020) = 7.893
CC) (1)

\section{Irri $\mathbf{H}^{1}$, Rajendran $\mathbf{S}^{2}$, Narasimhalu $\mathbf{C R}^{3}$, Sonti $\mathbf{S}^{\mathbf{4}}$}

\section{ABSTRACT}

Introduction: Basal cell carcinoma is the most common skin cancer. Pigmented basal cell carcinoma is a very rare variant of Basal cell carcinoma with increased pigmentation. Intermittent ultraviolet radiation exposure is the predominant risk factor. Due to its multiple and varied clinicopathological presentations, its diagnosis becomes difficult. A case of multiple pigmented BCC is reported in a 64-year-old manon the right cheek. The diagnosis was established based on histopathology and dermoscopy findings.

Result: Dermoscopy showed a maple-leaf like a pattern, blue-grey globules, ulceration and vessels. Histopathological examination showed an island of basaloid cells with peripheral palisading, melanin clumps in the stroma, with retraction artefacts.

Conclusion: Dermoscopic analysis of the pigmented basal cell carcinoma eliminated the need for biopsy leading to early diagnosis and prompt intervention. Thus dermoscopy should be used as a routine tool in suspected skin lesions.

Key Words: Pigmented basal cell carcinoma, Skin cancer, Dermoscopy, Basal cell carcinoma, UV radiation, Basaloid cells

\section{INTRODUCTION}

Basal cell carcinoma (BCC) is the most common nonmelanoma skin cancer with negligible mortality. ${ }^{1}$ However they exhibit significant morbidity if diagnosed late or left untreated. Pigmented basal cell carcinoma is a very rare variant accounting for about $6 \%$ of total cases of BCC. ${ }^{2}$ Pigmented basal cell carcinoma is commonly seen among black, Hispanic, and Asian individuals. ${ }^{3}$ They are less frequent in Caucasians. It mostly presents in the elderly with male preponderance attributable to their increased years of exposure to UV radiation. Biopsy of the lesion followed by histopathological examination have been the mainstay in diagnosis. Recently dermoscopy has become an important diagnostic tool aiding in differentiating pigmented $\mathrm{BCC}$ from melanoma

\section{CASE REPORT}

A 64-year-old male presented to skin OPD with chief complaints of dark coloured skin lesion over the right cheek of more than 3 years in duration and a similar lesion smaller in size which developed 6 months ago below and behind the right ear. A gradual increase in size was observed in the new lesion with mild itching. There was no appreciable increase in its colour.

On clinical examination, two well-defined plaques with irregular borders, with a central pinkish hue and surrounding hyperpigmentation, size measuring $4.5 \times 3 \mathrm{~cm}$ and $1.5 \times 1 \mathrm{~cm}$ were noted above the right angle of mandile and right infra auricular area respectively (Fig 1). The surface showed irregular pigmentation and was not tender or indurated on palpation. Differential diagnosis of basal cell carcinoma, squamous cell carcinoma and malignant melanoma were considered. Dermoscopic analysis was done which showed the absence of pigment network, focal area of ulceration, arborizing vessels, bluish-grey globules and leaf-like structures on the older plaque (Fig 2). Whereas the new plaque showed the absence of a pigment network with multiple ulcerations and bluish-grey globules (Fig 3). To confirm the diagnosis a punch biopsy was performed and sent for histopathological examination.

\section{Corresponding Author:}

Irri H., 102B Bhavani Residency, Saveetha Medical College, Chennai 602105, India.

Phone: 9618805565; Email:hariniirri21@gmail.com

ISSN: 2231-2196 (Print)

Received: 15.11 .2020
ISSN: 0975-5241 (Online)

Revised: 04.03 .2021
Accepted: 18.05 .2021
Published: 05.07 .2021 
Histopathology showed an island of basaloid cells with peripheral palisiding, and melanin clumps in the stroma, with retraction artefacts forming clefted spaces (Fig 4).

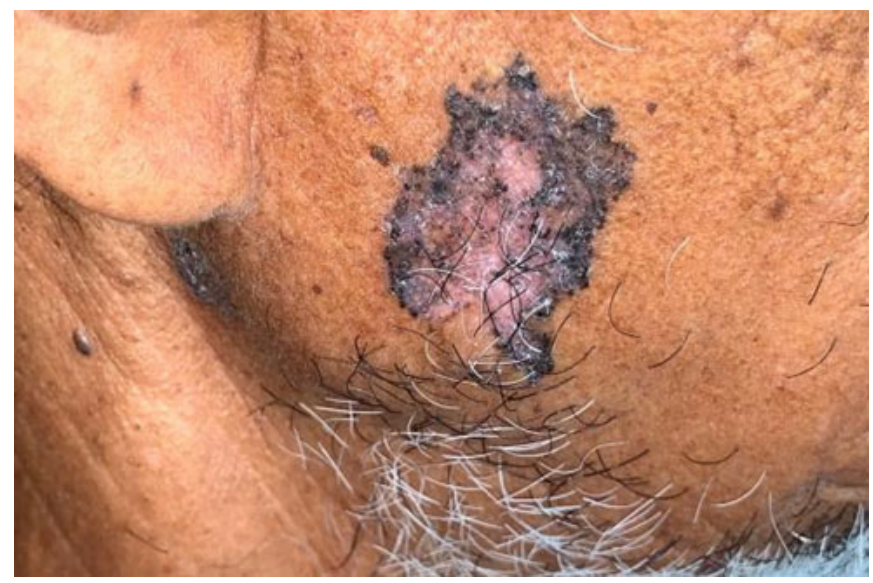

Figure 1: Solitary well defined indurated plaque with black brown pigment at the periphery and irregular border.

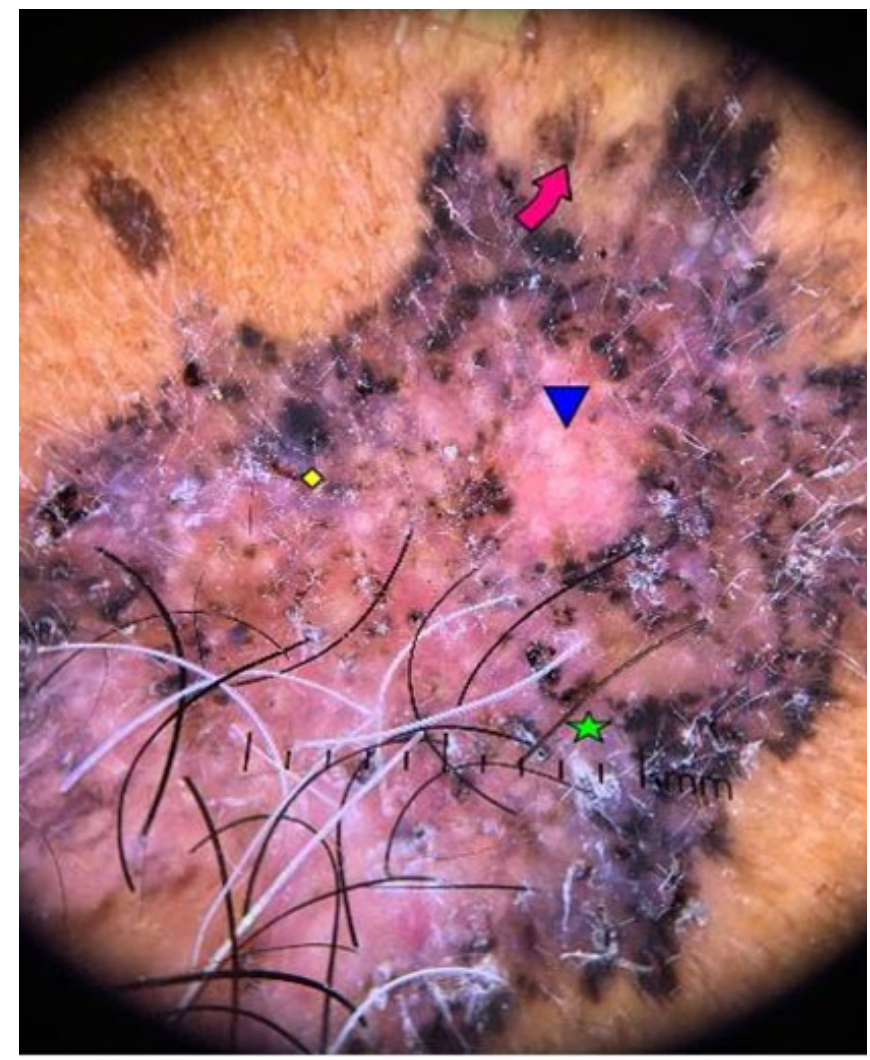

Figure 2: Dermoscopy findings: pink arrow - maple leaf like structures; yellow diamond - ulceration; green star - greyish blue globules; blue triangle - arborizing vessels.

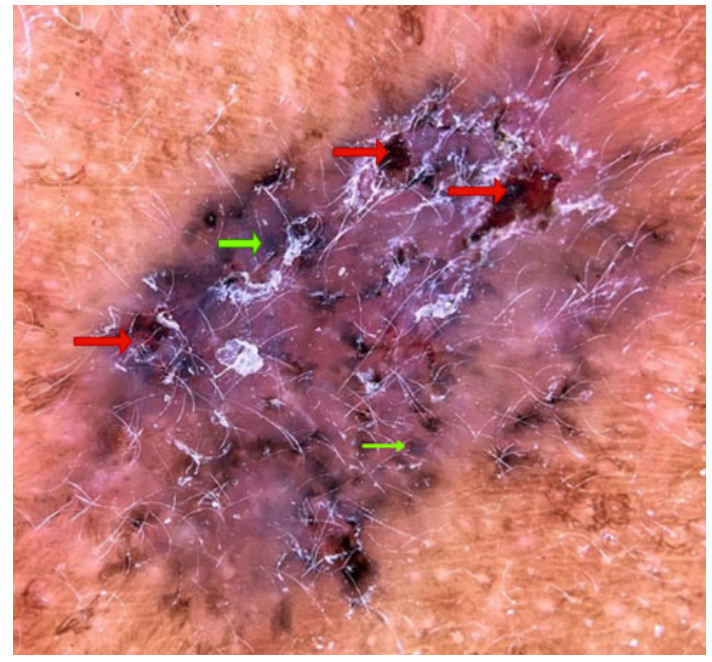

Figure 3: Dermoscopy findings: Red arrows: multiple ulcerations; Green arrows: bluish grey globules.

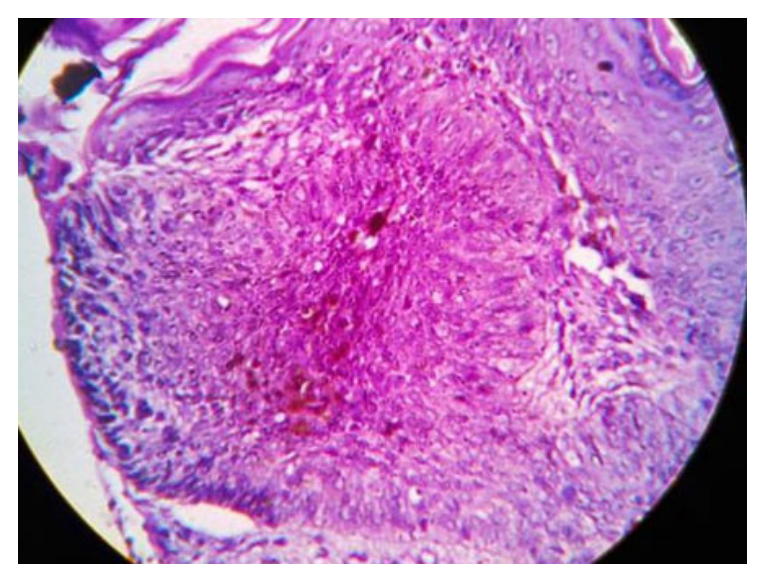

Figure 4: HPE shows peripheral palasiding, retraction artefacts with central clumps of pigmentation.

\section{DISCUSSION}

Basal cell carcinoma is a skin cancer originating from pluripotent cells in the basal layer of the epidermis or follicular structures. Non pigmented basal cell carcinoma is much more common than its pigmented counterpart. Pigmented basal cell carcinoma is a rare variant in which melanin is produced by melanocytes that colonize the tumour and in melanophages located in the surrounding stroma. It is a slow-growing, locally invasive tumour. ${ }^{4}$ Intermittent, intense exposure to ultraviolet rays from the sun plays a major role along with other risk factors like skin type 1 (never tans, always burns), red or blonde hair, and blue or green eyes in the development of basal cell carcinoma. ${ }^{5}$ In western literature BCC showed a female preponderance whereas in Indian literature there is a male preponderance. ${ }^{6}$ The risk of basal cell carcinoma is high among males above 60 years, the most common site being the middle third of the face but can occur anywhere on the 
sun-exposed parts of skin. ${ }^{7}$ Which is in line with our case, where a 65 years old man who was a farmer presented with a lesion on the face. A differential diagnosis of pigmented basal cell carcinoma and melanoma was considered.

Hence a noninvasive diagnostic aid was considered. Dermoscopy helps in the diagnosis of basal cell carcinoma from other pigmented lesions. Menzies et al proposed a simple dermatoscopic method for diagnosing pigmented BCCs. This method has a sensitivity of $97 \%$ and a specificity of $92 \%$ and $93 \%$ for differentiating pigmented basal cell carcinoma from melanoma. ${ }^{8}$ According to this diagnostic method, pigmented $\mathrm{BCC}$ must have a negative feature i.e absence of pigment network and presence of one of the following six criteria: maple leaf-like areas, blue-grey ovoid nests, ulceration, arborizing vessels, spoke wheel areas, multiple bluegrey dots/globules. ${ }^{9,10}$ This case fits well into the criteria with the absence of pigment network and presence of maple leaves like areas, focal ulceration, blue-grey globules and arborizing vessels.

The clinical and dermoscopic diagnosis was further substantiated with histopathological evidence consistent with pigmented BCC. Plastic surgeons and Oncologist's help were sought for further management and the patient is being followed up.

\section{CONCLUSION}

This report describes a pigmented variant of $\mathrm{BCC}$, which is a rare manifestation, diagnosed with classical histopathology and dermoscopy findings. Knowledge of dermoscopic findings in pigmented BCC helps to avoid unnecessary biopsies, aids in early diagnosis and management of the patient. Though a widely used modality it should be incorporated into daily clinical practice to enhance diagnostic accuracy.

\section{ACKNOWLEDGEMENT}

Authors acknowledge the immense help received from the scholars whose articles are cited and included in references of this manuscript. The authors are also grateful to authors/ editors / publishers of all those articles, journals and books from where the literature for this article has been reviewed and discussed.

\section{Conflict of interest - Nil}

\section{Source of funding - Nil}

\section{Author's contribution}

Irri $\mathrm{H}$ had contributed to the diagnosis and drafted the article. Rajendran S and Sonti S has made a substantial contribution to the diagnosis or design of the article. Narasimhalu CR had revised it critically for important intellectual content and approved the version to be published.

\section{REFERENCES}

1. Deepadarshan K, Mallikarjun M, Abdu NN. Pigmented basal cell carcinoma: a clinical variant, report of two cases. J Clin Diagn Res. 2013;7(12):3010-3011.

2. Khot K, Deshmukh SB, Alex S. Pigmented basal cell carcinoma: an unusual case report. J Case Report. 2015;4(1):189-92.

3. Abudu B, Cohen PR. Pigmented Basal Cell Carcinoma Masquerading as a Melanoma. Cureus. 2019;11(4): e4369.

4. Jain M, Madan NK, Agarwal S, Singh S. Pigmented basal cell carcinoma: Cytological diagnosis and differential diagnoses. J Cytol and Acad Cytolog. 2012;29(4):273.

5. Wong CS, Strange RC, Lear JT. Basal cell carcinoma. Bri Med J. 2003;327(7418):794-798.

6. Nandyal SS, Puranic RB. Study of the demographic profile of skin tumours in a tertiary care hospital. Int J Curr Res Rev. 2014;6(16):24-28.

7. Nagi R, Sahu S, Agarwal N. Unusual presentation of pigmented basal cell carcinoma of the face: a surgical challenge. J Curr Drug Res. 2016;10(7): ZJ06-7.

8. Lallas A, Apalla Z, Argenziano G, Longo C, Moscarella E, Specchio F, Raucci M, Zalaudek I et al. The dermatoscopic universe of basal cell carcinoma. Dermatol Pract Conc. 2014;4(3):11-24.

9. Senel E. Dermatoscopy of non-melanocytic skin tumors. Indian J Dermatol Venereol Leprol. 2011;77(1):16.

10. Rambhia KD, Shah VH, Singh RP. Dermoscopy of pigmented basal cell carcinoma. Pigment International. 2018;5(2):123-4. 